\title{
To engage or not to engage? That is the question: Students' perceptions of engagement at a West Midlands University
}

\author{
Jane Beniston and Deborah Harris, Newman University
}

\section{Introduction}

Student Engagement is a concept that has been widely researched, theorised and debated (Kahu, 2013:758), and now forms part of the rhetoric in and amongst universities. It is no coincidence that this interest has emerged in a time when students are facing ever increasing fees, amplified competition between universities, alongside the widening participation agenda where the focus has shifted to engaging more 'non-traditional' students, for example, mature students, part time students, students from areas of disadvantage or deprivation, and students from ethnic minorities (Trowler, 2010:23). However, little shared understanding of, or clarity about, the concept of 'student engagement' is evident within the literature and we would argue, alongside many stakeholders in Higher Education Institutions, that this may be owing to the dualistic nature of student engagement - in terms of what students and institutions have to do (Bryson 2014:17). Such lack of clarity is not helpful and, as Buckley (2014:2) states, "if we are not clear about what student engagement is, then our ability to improve, increase, support and encourage it... will be severely diminished."

Certainly, the discourse about student engagement presents it as 'a complex, multi-faceted, and socially constructed concept' (Kahu, 2013:758), "a dynamic, individual, meta construct" (Bryson 2014:19), "a multi-dimensional construct" (Axelson and Flick, 2011:41), a Market Model of student engagement versus a Development Model of student engagement (HEA, 2010:3) and a 'truly complex phenomenon (Solomonides et al, 2012:1). Together, these all serve to confirm that 'student engagement' is a complex concept, open to disparate interpretation, with the real risk that, in discussing it, HE institution stakeholders believe that they share a common understanding when they do not (HEA, 2010:4).

The overall aim of this study was to explore how student engagement could be developed at one university. The subsidiary questions of the wider study included: What is meant by student engagement? How do we engage 'hard to reach' students? How do we make student engagement more visible? This paper explores only the first of those questions, attempting to create some insight into definitions by students and current levels of engagement.

Newman University is a Catholic University located within a suburb of Birmingham. Currently, there are 2500 students, with $75 \%$ attending on a full-time and $25 \%$ on a part-time basis. $75 \%$ of students are female and $25 \%$ male. In terms of ethnicity, $62 \%$ are white, $10 \%$ black and $21 \%$ Asian. The remaining $7 \%$ of students are of mixed heritage or have not declared their ethnicity. Over twice as many students declare themselves to be Muslims as declare themselves to be Catholic. An overwhelming majority of students are from geographical areas which have the lowest participation in Higher Education. 93\% of students are classed as commuter students, having the same term-time address as their permanent address. Though the general student demographic chimes with the adage of 'hard to reach' students, Newman is seen as a thriving community, albeit not a residential one. The combination of all of the above factors do, however, present their own set of challenges around student engagement.

\section{Defining 'student engagement'}

There is, according to Buckley, (2014:4) "a range of phenomena to which the term 'student engagement' has been applied." A majority of the literature appears to be concerned with students' engagement in the learning process and improving this learning to ensure highquality outcomes for students. Hu and Kuh (2001:3) state that student engagement is "the 
quality of efforts students themselves devote to educationally purposeful activities that contribute directly to the desired outcomes" and Kuh et al (2007, cited in Trowler, 2010:7) state that student engagement is "participation in educationally effective practices, both inside and outside the classroom, which leads to a range of measurable outcomes". Both definitions raise interesting viewpoints, one being that student engagement is seen as a quantifiable and a measurable concept - which, as Bryson (2014) claims, is a naïve use of the National Student Survey (NSS) in the UK - and the other, that although staff and institutions can implement a range of strategies to support student engagement, ultimately 'effective' student engagement is driven by the agency of the students and not academics. Other literature (Trowler, 2010:4, Coates, 2005:26, Krause and Coates, 2008:493) analyses student engagement from a similar perspective, that it is a concept associated with what Kahu (2013) would categorise as a behavioural approach towards engagement. This behavioural approach is potentially achieved through "educationally purposeful activities" (Coates, 2005:20). These activities may include active or possibly experiential learning as opposed to 'traditional' lectures, content that is culturally relevant and sensitive to local contexts, working collaboratively with other students, participating in academic activities that provide challenge and being able to seek support from staff (Coates, 2005:26). These educationally purposeful activities need to be incorporated into effective pedagogy to encourage engagement, which consists, according to Krause and Coates (2008:494), of eight qualities:

- constructive teaching

- supportive learning environment

- teacher approachability

- student/staff interaction

- academic challenge

- collaborative work

- beyond class collaboration

- complementary activities

These behavioural aspects do need to be given careful consideration if we are to engage students in an academic capacity. Certainly, teaching needs to be constructive, but if students comply in terms of attendance and are willing to communicate and contribute to lectures, is this a true reflection of engagement, or is this classified simply as participation and good practice in Higher Education?

We need to be mindful of the fact that the above qualities may well illustrate excellent teaching or sound pedagogical practice, but quality teaching is not, as Leach (2013:118) points out, a proxy for student engagement. It could, however, be argued that, with the everpresent widening participation agenda resulting in working with a range of non-traditional students, participation in behavioural terms is in fact a fundamental aspect of student engagement and could be the catalyst for their engaging at different, wider levels throughout their time at university.

Further literature (Coates, 2005:26, Buckley, 2014:10, Krause et al 2005:38, Krause and Coates, 2008:503) acknowledges the importance of students' being engaged in the learning process through 'student-centred learning' and working collaboratively. In order to facilitate engagement at this level, a constructivist ideology around learning needs to be present, allowing for students to construct knowledge with each other and with academic staff. This co-construction of knowledge does not have to occur only within lectures, but can also be present in "beyond class collaboration" (Krause and Coates, 2008:494). Examples of this can be identified in the literature as students engaged as partners in research, students engaged in curriculum design or students engaged at an institutional level - although the literature on the latter appears to be sparse. What becomes apparent is that the role of the 
academic in both engaging students to collaborate and ensuring relationships between staff and students are nurtured is key to success in Higher Education (Krause et al, 2005:36, Thomas, 2012:8), which contradicts previous discussions around effective student engagement ultimately relying on the agency of the student.

\section{Models of student engagement}

The literature proffers a range of student engagement models: they present key ideas succinctly and do help to make clear what 'student engagement' really means. Coates (2007, cited in Trowler, 2010:12) presented the following model of Student Engagement Styles

Figure 1 Student engagement styles (Coates, 2007)

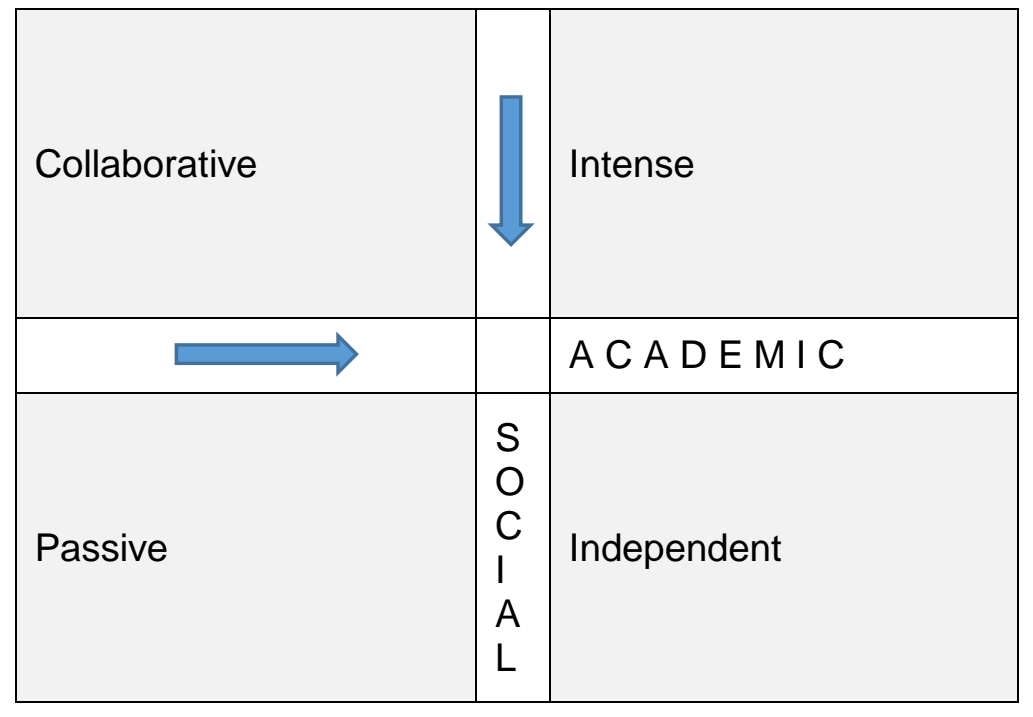

Figure 1 represents ways in which states of student engagement are perceived.

Students who identify that engagement is intense are "highly involved with their university study. They tend to see teaching staff as approachable and to see their learning environment as responsive, supportive and challenging" (Coates, 2007:132-133, cited in Trowler, 2010:13).

Students who identify an independent style of engagement also see staff as approachable; however, they demonstrate a more academically but less socially-orientated approach to study. (Coates, 2007:133-134 cited in Trowler, 2010:13).

Students who identify with a collaborative style of engagement tend to favour the social aspects of university life and work, as opposed to more purely cognitive or individualistic forms of interaction (Coates, 2007:134 cited in Trowler, 2010:13).

Passive engagement concerns students who "rarely participate in the only or general activities linked to productive learning" (Coates, 2007:134 cited in Trowler, 2010:13).

Coates is keen to emphasise that these are 'transient states' of engagement. There is no analysis of which state is considered a more effective mode of engagement; however, links can be made to common discourses in existing literature which appear to indicate the importance of both intensive and collaborative states for successful engagement. A study undertaken by Evans et al in 2015, which was funded by the Higher Education Academy (HEA), captured information from a vast range of literature about dimensions of 
engagement. An edited version, which hopefully captures the key information, is outlined below.

Table 1. Dimensions of engagement

\begin{tabular}{|c|c|}
\hline Dimensions & Indicators \\
\hline Cognitive & $\begin{array}{l}\text { - knowledge and understanding of the } \\
\text { - } \text { discipline } \\
\text { - } \text { skills - reading, writing } \\
\text { - } \text { research solving } \\
\end{array}$ \\
\hline Metacognitive & $\begin{array}{l}\text { - } \quad \text { critical reflection } \\
\text { - } \quad \text { analytical and critical thinking } \\
\text { - } \text { deep thinking } \\
\text { - } \quad \text { understanding of self }\end{array}$ \\
\hline Affective & $\begin{array}{l}\text { - } \text { attitudes towards learning } \\
\text { - } \text { motivation, interest, positivity } \\
\text { - } \text { holistic, well- being, identity } \\
\text { - } \quad \text { infidence, perceptions of competence } \\
\text { - environment - beyond limits of the } \\
\text { - } \quad \text { integramme } \\
\text { - }\end{array}$ \\
\hline Behavioural & $\begin{array}{l}\text { - } \quad \text { attendance, commitment } \\
\text { involvement/participation; immersion, time } \\
\text { on task } \\
\text { - involvement: interaction, participation in } \\
\text { dialogue, questioning, online presence, } \\
\text { contribution to teams, peer collaboration, } \\
\text { engagement with technology } \\
\text { - interpersonal } \\
\text { - } \quad \text { professionalism }\end{array}$ \\
\hline Students as producers & $\begin{array}{l}\text { - } \quad \text { student generation of content } \\
\text { - } \quad \text { student producers of resources } \\
\text { - } \quad \text { student producers of research } \\
\text { - } \quad \text { as partners }\end{array}$ \\
\hline Sustainability: Life skills & $\begin{array}{l}\text { - } \text { resilience } \\
\text { - } \text { emotional regulation } \\
\text { - } \text { flexibility } \\
\text { - independent thinking } \\
\text { - } \text { organisation }\end{array}$ \\
\hline
\end{tabular}

The above table is helpful in unpacking how student engagement can be perceived, drawing on both the academic and emotional aspects of engagement. It also identifies as a dimension of student engagement such aspects as life skills, something about student engagement not widely discussed within the literature.

Bryson (2014:9) presents a relational model of student engagement, adapted from Solomonides et al (2012), which identifies that Higher Education needs to provide students with a 'sense of being', allowing students to be confident, happy and imaginative and to possess self-knowledge. This may then enable a 'sense of transformation', by means of which the student is able to learn, think and understand, as well as to have knowledge of 
her/his discipline and self-knowledge, in turn generating a sense of engagement. This model implies that student engagement can be viewed as a process and that emotional well-being is an important aspect of successful engagement.

\section{Social and emotional engagement}

Harper and Quaye (2009, cited in Trowler, 2010:5) argue that engagement does need to be more than involvement or participation or collaboration in the learning process and that engagement requires "feeling and sense making". Without the latter, the concept of engagement is merely involvement or pure compliance.

The aspect of emotional engagement would appear to be a key factor when examining perspectives of student engagement. Findings from the What Works Report (Thomas 2012:12) which examined practices effective in producing student engagement, identified that it was essential to develop a culture in universities which instilled a sense of belonging, within both the academic and social community. Belongingness, according to Andrew and Whitaker (2012) is cited as a concept that involves feeling connected to the institution, being accepted, being valued, being included and encouraged by others and being connected to both the academic and curricular environment. This sense of belonging has the potential to have impact upon both academic success and retention. As Thomas (2012:1) states, "a sense of belonging is critical... it is the human side of Higher Education that comes first, finding friends, feeling confident and above all feeling a part of your course of study and the institution". However, Leach (2013:120) identified that, for students of an Asian background, a sense of belonging was not as important as feeling valued as a person and having one's culture recognised. With the expansion of Higher Education and the widening participation agenda, Krause et al (2005:3) highlight that universities are now "characterised by diversity of all kinds and institutions are keen to know how they can engage students from diverse backgrounds with diverse needs." This is reiterated by Coates (2005:26) who states: "we need to be mindful of the importance of creating an inclusive environment, one in which women, men of all cultures, nationalities, social economic and other backgrounds will, so far as possible, feel able to engage on equal terms".

Hand and Bryson (2008) refer to the work of Tinto (1993) and Perry (1999) which states that this concept of belonging is affected by the 'academic' experience that students feel that they have had, which is influenced by both the commitment of teaching staff and the social experience. Krause et al (2003) identified that students who met regularly in the wider range of social contexts, including reflecting on and discussing assignments, were more likely to have greater levels of satisfaction with their academic progress. Conversely, students who were least satisfied with their academic progress were identified as those students less actively socially engaged with their peers.

For most students, the idea of social engagement where the institution provided a sense of community was an important factor in enriching engagement. Milem and Berger (1997, cited in Krause et al 2003:3), state that opportunities for social interaction amongst students may be more important in motivating and encouraging them to persist in their studies than academic integration. Krause and Coates (2008:502) found that, for commuter students who may face many competing aspects in their life - such as juggling paid work with study and family responsibilities - being part of a community on campus was particularly important and where, according to Thomas (2012:18), friendships played a vital role by providing, through peer interaction, an informal support system.

According to Trowler (2010), the emotional dimension of student engagement may have been overlooked within research; however, a sense of belonging could potentially be a key aspect of engagement, certainly for some groups of non-traditional students such as those 
from different ethnic groups and commuter students. Although a 'sense of belonging' and 'feeling engaged' may be important to students, Bryson (2014:8) points out that academics appear to be more concerned with the students focusing on academic tasks and demonstrating what he calls "virtuous behaviours" rather than with emotional engagement. There is thus a potential disparity, between academics and students, in their interpretation of the concept of engagement, suggesting the need for all stakeholders to have a more common understanding of it.

\section{Methodology}

An a-pragmatic paradigm was undertaken, with the intention of facilitating the use of a mixed-method approach to the study. The a-pragmatic paradigm approach (Patton, 2015) was utilised as it was felt that philosophical assumptions in research are useful tools but that they should not drive the decisions about the design and method of the study. These decisions would be determined by the context and the construct of student engagement being studied. The researchers, both academics and students, had a major influence on this approach, coming as they did from backgrounds either dominantly positivist, engaging with numbers and quantitative data, or interpretivist, exploring words and qualitative data; an apragmatic paradigm was therefore the best fit. It was decided to embark on an inclusive philosophical framework within which multiple assumptions could comfortably reside. This allowed the use of a mixed-method approach to gather data on a human phenomenon. To reach as large a group of students as possible, across a variety of subject areas within the University, questionnaires were deemed an appropriate research method. Questionnaires were designed to facilitate both qualitative and qualitative responses comparing and contrasting varied definitions of student engagement. We needed to make sense of what we needed to know or, in other terms, develop a level of contextual meaningfulness. With this in mind, a case study approach was adopted, which allowed us to consider questions related to: "How do students construct their own meaning of the concept student engagement?", "How are they engaged or involved in university life"? Walliman (2011) considers case study approaches to be a useful tool for collecting quantitative data; however, owing to the nature of this study, qualitative data was also needed, especially with regard to definitions of student engagement. We did not want to prompt participant answers by offering choice; we wished rather to oblige them to formulate their own definitions, using personal language and terminology.

This main research tool was therefore designed to include both some standardised, structured data collection and opportunities for participants to respond in an individualised manner. This design would therefore elicit both quantitative and qualitative data and was intended to enable the researchers to see connections between the data sets. For example, would someone with a well-developed construct of student engagement be involved in a variety of engagement activities within the university?

The questionnaire was sent for approval to senior management, as gatekeepers, and their comments were integrated into the design, which focused on four key aspects:

- engagement with academic course or study;

- engagement with social events at university;

- engagement with extra-curricular activities;

- institutional engagement.

One issue identified by the students in the team was the language we were using in the questions. They felt it was not student-friendly and therefore needed adapting, to avoid what Cohen et al (2000:249) would call 'highbrow questions'. The questionnaires were also 
piloted by students from a neighbouring university, as the sample group was comparable. The pilot highlighted the need for minor changes to some closed questions to ensure clarity. The aim of the sample was to capture views of undergraduate and postgraduate students studying at Newman University. This was a total of 2,500 students. It was hoped to capture as many participants as possible to make this sample representative of the population of students at our university. A probability sample (Cohen et al, 2000:99) was employed to ensure that any member of the wider population would not be excluded from the research. However, owing to time constraints and issues about access to students, a total of 235 questionnaires were administered in eleven different subject areas within the University to $9.4 \%$ of the total population. This covered all schools within the University and was deemed as representative a sample as constraints would allow. University ethics procedures were followed, with ethics approval granted by the Ethics Committee.

The response rate for questionnaires was low: only 149 were returned fully completed. Data sets were initially considered in isolation, then mixed and analysed again at the point of interpretation. Quantitative data was coded using SPSS to allow statistical comparisons and connections to be made. Qualitative data sets were coded using a crude discourse analysis system looking for commonality of wording, phrases and definitions.

\section{Findings}

From analysis of data, three categories of student engagement emerged - academic, social and extra-curricular/institutional - which are presented in the findings. Key themes that arose from the findings, such as communication, marketisation of $\mathrm{HE}$, commuter students and belonging are explored in the discussion.

\section{Academic engagement}

The dominant discourse arising from the data clearly identified that students consider engagement as being related to some aspect of their studies or course; $51 \%$ students alluded to this 'academic engagement'. Responses stated that engagement was about interaction with lectures, seminars and activities. Of these responses, $83 \%$ participants felt it was students' engaging with their course materials and learning, rather than with other people; only $17 \%$ mentioned interaction with lecturers and other students. Many students used the words 'engagement', 'engaging' and 'engaged' in their responses, without giving any further definitions; however, two key terms did emerge: 'participation', 43\%, and 'involvement', 32\%. Other interesting key words used were 'showing', 'responding', 'contributing', 'cooperating' and 'connecting'. These all highlight an active nature of engagement but also allude to engagement being with other people, not just course content or learning materials; however, they were not the dominant terminology.

Responses by participants as to why they attended lectures and seminars varied from the consumer element of paying for the course, to gaining information and meeting the assignment criteria. However, some students, particularly in second and final years, considered lecture attendance crucial to gaining knowledge and understanding, rather than information. Participants perceived engagement through individual tutorials as valuable for one-to-one support and guidance. Participants engaged in discussions if they felt they had something to say and the group was small.

Most participants felt they completed between 1-5 or 6-9 hours of independent study in a week. This seems a low figure as most full-time degree courses, within the programme guidelines, require 40 hours' independent study per week. Reasons given for lack of attendance, and maybe low independent study time, are work commitments, health issues and long journeys to University. This chimes well with the $93 \%$ commuter student intake. 
Over half the participants stated that they engage with the Virtual Learning Environment Moodle - mostly for assignment guidance, lecture information and PowerPoint presentations; however, no-one mentioned forums or discussion boards. Many participants access the library, mainly for books and academic study; however, very few see it as a social space to collaborate with other students. They see participation through email and face-to-face contact as a key way to engage with course content. However, social media was also found to be a dominant category; this seemed to be down to students' creating their own groups. In terms of accessing other services provided, IT support was the most popular, with student services following closely behind. A negligible number of participants had not accessed any services provided.

\section{Social engagement}

When attempting to define 'student engagement', $30 \%$ of questionnaires referred to a definition that potentially had some link to social engagement. From this data, student engagement was typically defined as 'engaging in social activities', engaging in social activities with staff', 'engaging in student life', 'involvement with other students', 'working together as a team' and 'how involved a student is with people and the environment'. From further analysis, two common themes emerged: 'engaging in social activities' and 'working collaboratively outside lectures'. However, despite these being the two main themes, only a small percentage of students identified these concepts as relevant to student engagement. $5.3 \%$ of students referred in their definitions to the concept of social activities' being a part of student engagement. In spite of this, a higher percentage of students could identify which social events they had attended. From the 149 students surveyed, $11.4 \%$ had attended quizzes, $19.4 \%$ had attended trips and $27.5 \%$ had attended parties. These statistics do however, indicate that there is a large percentage of students who do not perceive social engagement to be an aspect of student engagement, nor do they engage in planned social events. Many reasons were given for this, with four dominant themes emerging: 'levels of interest', 'employment', 'communication' and 'commuting'.

A total of $95.3 \%$ students surveyed were identified as commuter students and, of the $4.69 \%$ of students who did live on campus, $2 \%$ of these students were Erasmus students, whose campus accommodation was provided as part of their temporary stay at the University. Commuter students had varying travelling distances from home to the University, from ten minutes up to two hours by public transport. This has a major impact on students' engaging with planned social events: many stated: "I live too far away", "I only come in for lectures", "I don't drive and uni is a bit of a distance from home", "living off campus it takes too long to come in just for a quiz or a part", [I don't engage] "because I don't live on campus." Students also reported that the types of social activities arranged were "boring", "there are not enough trips", "there is not anything that interests me", "not my scene", "I have better things to do", "I don't feel it's beneficial to me", "not my thing".

A small number of students, 3.3\%, explicitly stated that these types of social events were not appropriate; "parties are not for Muslim students", "I am a part time student and feel friendships have already been made", "these don't feel relevant as an older part time student", "I am over 50 so I don't feel I would fit in", "because I am a mature student and do not live in hall", "as a mature student, I don't find these relevant".

Poor communication in relation to knowing about social events was evident within the data. When questioned as to why they did not attend social events outside lectures, $16.7 \%$ of students responded with comments such as "I have never been told about these", "I am not aware of any events", "We do not hear about them", "I don't know when they take place", "I find out when it is too late", "I'm never invited or told anything about them", "I wasn't aware we did quizzes and I don't like parties". A high percentage of students also identified that 
being employed was a major barrier to social engagement. $93.2 \%$ of students across all programmes are employed, with a majority of students employed on a part-time basis, but some students are employed on a full-time basis on programmes such as Early Years Initial Teacher Training, which offers an Employer-Based Route. Being employed deterred students from engaging in social events, owing to time constraints.

A high percentage of students, $96.64 \%$, did identify that they used the social spaces provided within the University environment, the spaces where refreshments could be bought being the most popular. These spaces also provided students with areas of the University where they could work collaboratively. Many students referred to working collaboratively when attempting to define student engagement, stating it is about: "interacting", "working together as a team", "getting together and working together" and "engaging socially and helping each other out." Only one student stated that student engagement was about "engaging with both studies and friends", although other students did state that student engagement is about being involved with other people. There was a lack of data regarding students' identifying that they felt a 'sense of belonging'. No student indicated that student engagement was about feeling that they 'belonged' to the University.

\section{Extra-curricular and institutional engagement}

Another theme that emerged from the data was students' defining student engagement as extra-curricular or institutional engagement. $20 \%$ of questionnaires made some reference to this in their definitions of student engagement, with responses such as [student engagement is] "having involvement in uni life", "engaging in university societies", "being engaged in university matters", "getting involved in the wider university life", "involvement in extracurricular activities" and "being involved in all aspects of university." Further analysis indicated that, in terms of extra-curricular engagement, 36\% students stated that they attended workshops (for academic support) and training, citing examples such as Phonics Training, Safeguarding, Prisoner Families, Ofsted and Leadership. Reference was also made to attending specific conferences held, with $19 \%$ stating they had participated. $25 \%$ confirmed that they attended educational trips, although this was not qualified further in terms of destination. Only a small number of students, 9.3\%, had attended Children's University sessions and 10\% had been involved in Student as Academic Partners or Student as Academic Research Partners projects.

In terms of being engaged at an institutional level, a high percentage, $67.7 \%$, stated that they voted at student elections. However, there was also evidence that this may have been through coercion! Students were engaged in a wide range of other institutional areas: $19.4 \%$ were Staff/Student Representatives, with 16\% employed as Student Ambassadors. However, the percentage of students who had been involved on committees or on validation panels was low, at $5.3 \%$. Reasons were given by students for not engaging more widely within the University and these responses to some extent mirrored previous responses for non-engagement, with the dominant discourses reflecting lack of interest, lack of time, not seeing the relevance of wider engagement and not being aware of opportunities available to them.

\section{Discussion}

Findings suggest that the majority of students see engagement as an interaction with course materials to achieve a successful degree. This resonates with work by Hu and Kuh (2001: 3 ), who state that student engagement is "the quality of efforts students themselves devote to educationally purposeful activities that contribute directly to the desired outcomes" and the idea of behavioural engagement is clearly identified in a raft of relevant literature. Students clearly identified that student engagement is about 'participation' and certainly models of 
student engagement and other literature (Harper and Quaye, 2009, cited in Trowler, 2012:5, Evans et al, 2015) feature participation as an element of student engagement, but does participation equate to engagement? Other institutions need to consider this in the light of their own definitions and measurements of student engagement. The marketisation of Higher Education could be one reason why students identify with engagement in this limited way: they see lectures and course content as a tangible means of gauging how they get value for money. Certainly, responses from students did pursue the Market Model of student engagement (HEA, 2010:3). Additionally, work commitments and commuting may restrict opportunities for engaging more widely and a high proportion of students indicated that they experience both of these barriers. In what is currently a climate of excessive testing in schools, the pressure to achieve in exams and the link to league tables have maybe influenced students' perception of engagement. The point of university therefore for some students is being able to gain a good degree, which, in their minds, can be achieved only through attending formally-taught sessions. Wider engagement is not therefore deemed necessary. This aspect of engagement embodies the Behavioural Dimension of Engagement as outlined by Evans et al (2015) and Kahu (2013), in that students relate engagement to attendance, involvement in tasks, questioning, participation in dialogue, peer collaboration and having an online presence. The findings also indicate that students also represent what Coates (2007) refers to as 'independent engagement', where staff are seen as approachable but students have a less socially-orientated approach to study. Again, this could be accounted for by the high percentage, $93 \%$, of commuter students. There is a high level of engagement with other people, through such provided services as Student Support, Library, IT support; however, these services provide a means to an end, so that students can be supported to gain the best academic outcome possible.

There seems to be a very low level of social engagement within the institution. This may be worth investigation in other institutions with lower levels of commuters. Evidence suggests that the types of social activities planned are not engaging a high majority of students, particularly those who could be labelled 'hard to reach' - i.e. mature students and students from predominantly Muslim families. More importantly, the types of social activities planned are not appropriate for some of our 'non-traditional students'. However, we must remember that, with a commuter population of $93 \%$, students may not come to university expecting to make friends and socialise as they may already have a circle of friends in their home location.

Nevertheless, as an institution, we need to do more to ensure that we are providing an inclusive environment that respects and values students from all backgrounds and cultures and provides social activities that encourages all students to engage on equal terms (Coates 2005). This may be worth investigation in other institutions. In addition to this, it is perhaps necessary for all institutions to rethink not only the nature of the social events planned, but also - owing to the high percentage of students who work as well as study - the timing of them. Consideration also needs to be given as to how students are informed about events, as lack of communication and not knowing about events was a clear theme dominating responses about social engagement.

There was a lack of data related to students' identifying that they felt a 'sense of belonging'. No student indicated that student engagement was about feeling that s/he 'belonged' to the University. This was quite surprising, considering that the University has such a small number of students and contradicts the idea presented in the literature (Krause and Coates, 2008; Thomas, 2012), that, for commuter students, being part of a community on campus, where friendships play an important role, is particularly important. This may differ in other institutions with lower commuter percentages, but is worth investigating. Further research needs to be undertaken with different groups of students to explore this concept further. It may be that social spaces need to be developed to allow for social collaboration with a focus on learning rather than on making friends, as, according to Krause et al (2003), social 
spaces that enable students to reflect and discuss assignments contribute to a greater level of student satisfaction with academic progress.

There is evidence of wider engagement both at a curricular and institutional level, especially a high percentage involved in student union voting. This resonates with the Evans et al (2015) model which identifies an 'affective dimension' of student engagement, where students have interaction beyond the limits of the programme. Students also attend additional workshops and training - as this could support students' future professional practice, it may be a motivation for attending: students may see the links between training and practice. This again links to the idea of success and Hu and Kuh's (2001:3) 'desired outcomes'.

\section{Conclusion}

The majority of students perceive engagement as related to involvement and participation in their programme, which was identified through comments about attendance, participation in dialogue, questioning and peer collaboration. We need to move beyond the idea of 'involvement' and 'participation' to consider how knowledge and understanding of wider student engagement can be developed. It would be beneficial for other institutions to investigate their own students' understanding of engagement, to develop a collaborative definition.

From this initial study, it would appear that there are certain barriers to students' engaging more widely within the institution. These concern lack of communication, work commitments and, within this institution, being a commuter student. Examples of good student engagement practice should be more widely disseminated and opportunities for wider engagement made more visible, to improve communication about engagement opportunities. All institutions need to consider the unique identity of their students to begin to tackle the barriers to engagement.

The definition of 'student engagement' across our institution still remains elusive and further research is needed to investigate definitions from other stakeholders.

\section{Reference list}

Andrew, N. and Whitaker, R. (2013) Promoting individualism and retaining identity in mass higher education: academic advising for the $21^{\text {st }}$ Century. Available at:

www.enhancementthemes.ac.uk (Accessed: 8 November 2016).

Axelson, R. D. and Flick A. (2011) 'Defining student engagement, Change.' The Magazine of Higher Learning, 43(1), 38-43. DOI: 10.1080/00091383.2011.533096

Bryson, C. (2014) 'Clarifying student engagement.' In: Bryson, C. (ed.) Understanding and developing student engagement. London: Routledge, 19.

Buckely, A. (2014) 'How radical is student engagement? (And what is it for?).' Student Engagement and Experience Journal, 3(2). Available at:

http://dx.doi.org/10.7190/seej.v3i2.95 (Accessed: 22 May 2017).

Coates, H. (2005) 'The value of student engagement for higher education quality assurance.' Quality in Higher Education, 11(1) 25-36. DOI:10./13538320500074915

Cohen, L., Manion, L. and Morrison, K. (2000) Research methods in Education. London: Routledge Falmer. 
Evans C., Muijs D. and Tomlinson M. (2015) Engaged student learning; high impact strategies to enhance student achievement. York: Higher Education Academy.

Hand, L. and Bryson, C. (2008) Student engagement. London: Staff and Education Development Association.

HEA. (2010) Framework for action: enhancing student engagement at the institutional level. York: Higher Education Academy.

Hu, S. and Kuh, G.D. (2001) 'Being (Dis) Engaged in Educationally Purposeful Activities: The Influences of Student and Institutional Characteristics.' Paper presented at the American Educational Research Association Annual Conference. Seattle, WA, 10-14 April.

Kahu, E. (2013) 'Framing Student Engagement in Higher Education.' Studies in Higher Education, 38(5), 758-773 DOI: 10.1080/03075079.2011.598505

Krause, H. and Coates, H. (2008) 'Students engagement in first-year university.' Assessment and Evaluation in Higher Education, 33(5), 493-505.

Krause, K. Mclnnis C., and Wells C. (2003) 'Out-of-class engagement in undergraduate learning communities: The role and nature of peer interactions.' Paper presented at the Annual meeting of the Association for the study of Higher Education. Portland, OR, November 13-16, 2003).

Krause, K., Hartley R., Janes R. and Mclnnis C. (2005) The first year experience in Australian Universities; findings from a decade of national studies. Canberra: AGPS.

Leach, L. (2013) 'Engaging ethnically diverse first year students. A practice report'. The International Journal of the First Year in Higher Education, 4(2) 117-124.

Patton, M.Q. (2015) Qualitative research \& Evaluation methods: Integrating theory and practice. London: Sage.

Solomonides, I. Reid, A. and Petocz, P. (2012) Engaging with Learning in Higher Education. Faringdon, UK: Libri Publishing.

Thomas, L. (2012) Building student engagement and belonging in Higher Education at a time of change: final report from the What Works? Student Retention and Success programme. London: Paul Hamlyn Foundation.

Trowler, V. (2010) Student engagement literature review. York: Higher Education Academy.

Walliman, N. (2011) Your Research project. $3^{\text {rd }}$ edn. London: Sage. 